\title{
ANECDOTES, SITUATIONS, HISTORIES - VARIETIES AND USES OF CASES IN THINKING ABOUT ETHICS AND DEVELOPMENT PRACTICE ${ }^{1}$
}

Des Gasper

October 1999

Working Paper Series No. 300

\footnotetext{
${ }^{1}$ The first version of this paper was written for an EIDOS conference on The Ambiguous Relations Between Power and Morality: practices of intervention in development, held at SOAS, University of London, June 18-20, 1998. I am grateful to the organizers James Fairhead, Jennifer Law and Philip Quarles van Ufford for their invitation, and to participants, especially Johan Pottier, for reactions. I also thank participants in seminars at the Universities of East Anglia, Illinois, Kerala and Maryland, and Raymond Apthorpe, Jan Kees van Donge, Pim de Graaf, Mozaffar Qizilbash, Onora O’Neill, Robert Stake and three anonymous referees for comments and advice.
} 



\section{CONTENTS}

1. WHAT CAN WE DO WITH CASES IN DEVELOPMENT PRACTICE? 1

2. VARIETIES OF 'CASE’ OR EXAMPLE 4

Thick case studies: standard research advice and beyond 5

$\begin{array}{lr}\text { Thin case studies } & 9\end{array}$

$\begin{array}{ll}\text { Real-life choice situations - with or without advice } & 11\end{array}$

$\begin{array}{ll}\text { Real-life anecdotes and other illustrations } & 13\end{array}$

$\begin{array}{ll}\text { Conceivably true fictions } & 16\end{array}$

$\begin{array}{lr}\text { Impossible fictions } & 19\end{array}$

$\begin{array}{ll}\text { Refinement of the classification? } & 21\end{array}$

3. 'THICK' VERSUS 'THIN': WHAT MAKES CASES RELEVANT, $\begin{array}{ll}\text { AND FOR WHAT? } & 23\end{array}$

The importance of being concrete and of being thick ? - I: exemplars and vicarious

$\begin{array}{ll}\text { experience } & 24\end{array}$

$\varnothing y$ yus on the ethics of transfer of ox-cultivation to the Toposa 28

The importance of being thick? II: A communitarian claim 32

The virtues of slimming - O'Neill on excluding irrelevant details when assessing

$\begin{array}{ll}\text { justice } & 36\end{array}$

The importance of being concrete and thick ? - III: moral exemplars

$\begin{array}{ll}\text { and moral motivation } & 38\end{array}$

4. VARIETIES OF TASK AND ARENA 40

$\begin{array}{ll}\text { REFERENCES } & 44\end{array}$ 



\begin{abstract}
Anecdotes of development practice help to give us questions. Philosophers proceed with reflections on simplified abstracted situations of moral tension and choice, which serve to sharpen and organize concepts. Anthropologists amongst others provide extended histories of policies, projects, organizations or individuals, which may go deeper than anecdotes and abstraction, and which rely on yet can enrich their heritage of questions and concepts. Referring to a number of case studies, anecdotes and abstracted choice situations, the paper considers the range and roles of different types of cases in trying to better understand tensions, conflicts and choices in development. Diversity of purposes as well as of philosophies underlies the variety of recourse to cases. Since various purposes are legitimate and complementary (such as sensitization, theorization, informing decision-making) so too are various styles and uses of cases, including some thick (including a lot) and some thin (leaving out a lot). While thick description can provide peculiarly instructive and even inspiring exemplars, it is not always helpful in moral argument. Ideas about conditional relevance are synthesized into a picture of distinct stages in work in ethics and practical reasoning.
\end{abstract}





\section{WHAT CAN WE DO WITH CASES IN DEVELOPMENT PRACTICE?}

Pim de Graaf, now a Médecins Sans Frontières manager in Amsterdam, earlier worked as a doctor in an area in Southern Tanzania. Most 8-12 year old children in this area had bilharzia and hence sometimes urinated blood. Those who did not pass blood were considered sick and were treated by traditional doctors. At a conference (NVCO, Soesterberg 1997) de Graaf recounted the situation and the choice he faced. He decided not to intervene, or even seek to dispel the beliefs, for he feared he would make the majority of the children feel ill and their parents feel guilty, in circumstances where a sustained supply of anti-bilharzia drugs could not be expected.

Two diametrically opposed responses emerged in reaction to de Graaf's story. Group A held that he should have supplied medical information, to open a dialogue and permit people to make better-informed choices; not to do so was to treat them as moral infants. Group B held that local practices must be presumed appropriate. They argued that Western medical practices should not be promoted, being often deeply flawed and also generally inconsistent with local resources and culture, which must instead be strengthened and built upon. De Graaf himself in effect formed a Group C, who abstained from intervention but not because of doubts about Western medical knowledge. He perceived the situation as a genuine dilemma: between giving people more awareness and choice and leaving them more happy. The case served well in surfacing profound disagreements about medicine, 'communities' (a favourite category in Group B, but suspect in Group A), and 'development' (a term discarded by Group B, but retained in Group A). It provided no easy route to reducing these disagreements.

Case material is vital, but can be random, casual, bewildering. Referring to published and unpublished cases, including case studies proper, anecdotes and abstracted choice situations, I will try to consider the roles and limits of various types of case in improving understanding of ethical tensions, conflicts and choices, with special reference to development interventions and practice and to emergency relief. ${ }^{2}$ The focus on 'development' brings a distinctive set of inter-cultural, inter-national, inter-

\footnotetext{
${ }^{2}$ Not only North-South development cooperation is 'development intervention'. For background on development ethics, see e.g. Crocker (1991), Goulet (1995), Gasper (1994, 1997).
} 
income strata, and inter-generational concerns; but most of the paper is relevant for other contexts too. The discussion, it must be stressed, considers types of case and illustrates their employment by various authors; it does not centre on drawing substantive conclusions about the examples presented. Even if some comments are given in passing, these are either views of the authors cited or are provided to add flavour and thus to suggest ingredients and issues involved in deciding in and from cases, not more than that.

We are regaled with anecdotes of the invincible horrors, hyper-complexity, hypocrisy, and unintended negative effects of development interventions; or--now less frequently than earlier--of the reverse. Anecdotes can serve to give us questions, and to convey some aspects and varieties of experience. But they lack depth, a systematic basis of comparison, and, often, a sense of inquiry. We must go further. I will take as starting point that: development interventions involve numerous and diverse actors with differing power, world-views and values; development raises profound and often disturbing value-questions; some eyes of the strong(er) are blind and some open, the weak(er) also have weapons, and history has ironies as well as tragedies; and that "“development" is...a multi-faceted, multi-vocal process, and a complex site of contestation', beyond any one agent's powers to foresee and control (Grillo \& Stirrat, 1997:vii). In such contestation and vocalizing, agents frequently, perhaps increasingly, seek to define and defend themselves and influence others through ethical statements and systems.

Analytically inclined philosophers proceed with reflections on simplified abstracted situations of moral tension and choice, which can serve to sharpen and organize some concepts and intuitions. When one reads the work on ethics by many (not least Anglo-American) philosophers, and indeed some Northern social scientists, one is liable though to weary of their narrow (and often only implicit) sets of experiential source materials. When the materials are less narrow, they have sometimes been questionably derived. Ernest Gellner complained for example of 'scandalously irresponsible, scissors-and-paste, selective use of ethnographic material' by Northern philosophers seeking self-sufficient moral communities in the South (1974: 145).

Anthropologists provide extended case histories -- of policies, projects, organizations or individuals -- which sometimes go further than do anecdotes and abstraction 
and deepen their own heritage of questions and concepts. When one reads these experientially richer case studies -- also by some sociologists, political scientists, development practitioners and journalists -- one must however ask: How valid is the account? How good is the sample? (the sample of events and aspects from the case; the sample from cases of the type concerned; the sample from different types of situation). What is the question? (so that one can judge 'valid for what?' and 'a good sample for what?'). Can highly varied vignettes serve to give any cumulative and inter-subjective advances or consensuses? How can we make case studies into more than lengthy anecdotes -into generators and tests of new insights, sources of more adequate theory? How could we think more systematically and deeply about the ethical issues raised by cases -what concepts and frames are available and do they help? ${ }^{3}$

One theme in the paper, already apparent, concerns the different predilections, contributions and limitations of various disciplines and professions. This will be elaborated in Section 2, which offers a heuristic taxonomy of types of situation referred to in ethical and other practice-oriented argumentation: thick case studies; thin case studies; real life choice situations; real life anecdotes and other illustrations; conceivably true fictions; and impossible fictions. It uses this classification to present a wide range of cases used in discussion of or for development practice; and also considers possible refinements of the classification.

A second theme concerns the choice between richer cases and more selective ones, being thick and being thin, and the underlying differences in philosophy or purpose. Section 3 will examine both some weak claims for thickness--that detailed description of a culture will give us the culturally mandated answer to choices faced; or that more detail always helps us understand a situation better-and stronger ones, in

cluding the potential roles of thick cases in suggesting patterns, promoting a holistic grasp, and giving inspiration.

\footnotetext{
${ }^{3}$ The terms 'ethics'/ 'ethical' and 'morals'/ 'moral' are sometimes interchangeable -- not surprisingly, since one represents a Greek root and the other a Latin root. Where distinct, 'morals' refers to issues, views and rules concerning what is right/wrong/good/bad, and 'ethics' concerns theories and general approaches and principles about morals. Hence one sense of 'ethics' is 'moral philosophy'.
} 
A subsidiary theme crisscrosses the first two: how distinctive considerations in normative and ethical argumentation sometimes justify conclusions about the use of cases that differ from when purposes are descriptive or explanatory. For example, not only is more information sometimes unnecessary, certain types of information can be undesirable as they could bias decision-makers. The needs to motivate impartiality and yet concern, and reflection yet also action, generate their own styles of recourse to cases.

A last theme is thus that a wide range of types of case is in large part justifiable. Practical action and associated analysis call for a mix of types of thinking and feeling and willing, and correspondingly a range of types of use of cases. Notwithstanding the differences between philosophies and disciplines, all the styles that we will see can be legitimate when in their appropriate niche or role. As a rough working model, I suggest a picture of thought in ethics and reflective action as involving distinct stages, with distinct purposes and correspondingly different methods and use of cases. They are stages in the theatrical sense rather more than the chronological, for they must coexist and inform each other. For example, for mobilization of attention, concern, sympathy and energy, particular types or versions of cases serve well, often somewhat simplified but showing real people. Second, the choices thrown up by cases are tackled by those engaged, using whatever resources of thought and emotion were mobilized and are found relevant: such as intuitions, predictions of outcomes, posited rules of responsibility, and imagined role reversals (Jamieson, 1991). Where people find these resources insufficient or in conflict they may turn to explicit theorizing. More drastically simplified, depersonalized, cases may be used to help in this innovation or elaboration of concepts and systematization of frameworks. When we try to apply theories to rich, complex situations and to draw conclusions, we need further skills in selecting, adapting and combining ideas from theory, of facing and working with real people, and of practical idealism.; and we can strengthen these by reflection on rich, real, detailed cases. This picture will be returned to in the final part of the paper.

\section{VARIETIES OF 'CASE' OR EXAMPLE}

Let us consider types of case or example under six main headings: (1) thick case studies, (2) thin case studies, (3) real life choice situations, (4) real life anecdotes and 
other illustrations, (5) conceivably true fictions, (6) impossible fictions. We begin with the ideal of anthropologists, the thick case study; pass through more routine examination of choices and use of examples; and proceed towards what philosophers and economists often engage in, together with novelists: reflection on fictions. I do not propose that thick case studies are the ideal for all purposes or that we can dispense with the other types of case and example. At the end of the section I refine the classification. $^{4}$

\section{Thick case studies: standard research advice and beyond}

Let us start from standard research methods discussions about the relative strengths and weaknesses of in-depth studies of single instances. Those discussions are limited for they consider only descriptive and explanatory purposes. Methodological debates in ex post evaluation bring us towards a fuller set of relevant criteria for assessing use of cases in normative analysis.

Research methodology literature contains plenty of advice on what makes a good case study and the limits of even the best. Respective strengths and weaknesses and the potential complementarity of analytic and holistic approaches in descriptive and explanatory studies are well-known. ${ }^{5}$ Standard criteria apply: studies should be valid (accurate, with respect to the intended variables), reliable (reproducible by others to give the same results), and preferably broad in scope and representative of other cases too. Reliability and accuracy (internal validity) typically pose problems, as does representativeness (external validity). Single case studies cannot sustain generalizations, but instead generate insights and hypotheses as well as provide some understanding about the specific cases. For these, case studies are often stronger on 'band

\footnotetext{
${ }^{4}$ We should note already that 'case' can mean an instance (a situation/event/person/...) or a representation of an instance. In referring to the latter, we reserve the term 'case study' for representations with some degree of depth. In the literature on qualitative research methods the term can be further restricted, to study of a system 'bounded in time or place' (Creswell, 1998:40), such as an organization, project, policy, decision or whatever. The case-study tradition so defined overlaps with but is distinguishable from other qualitative research traditions like biographical study, phenomenology (investigation of the meanings of a phenomenon for participants), and ethnography (a portrait of a broad cultural system). However in this paper all are called case studies.

${ }^{5}$ See e.g. Bulmer \& Warwick (eds., 1983), or Patton (1997), for comparisons of surveys or experiments as against individual in-depth case studies, and also of larger with smaller samples. Larger samples usually bring both narrower scope and significantly increased non-sampling error.
} 
width' (scope): 'providing answers to a wide array of questions rather than [precise information on a] single question' (Shadish et al., p.310).

For evaluation of ongoing or completed social programmes and most development programmes, Stake and others call for priority to 'bandwidth', broad-ranging observation, and hence for rich, open-ended case studies. ${ }^{6}$ This allows one to be rough but relevant, rather than precise but misleading through sticking to a flawed pre-set observational frame, typically given by pre-set programme objectives. Evaluation should be responsive rather than preordinate, to use Stake's terms. It should examine the range of actual effects, many of which usually are unforeseen, not only consider intended effects (Hirschman, 1967; Gasper, 1999b). In 'responsive evaluation' the focus and criteria for the evaluation emerge and evolve in response to the digestion of evidence and to discussions with stakeholders. In this process one learns more about values as well as about outcomes and linkages. New and revised values and foci can emerge through reflection from widened experience. The traditional anthropological case study with its unhurriedness and broad scope can serve this approach; but so too might more rapid modern appraisal methods, if teams and participation provide the breadth of perspective and ability to question and rethink categories, focus and criteria.

Stake's critics argue that one could be both responsive and preordinate: one can have a prior focus in evaluation that is allowed to evolve. This is true, but in practice pre-ordination tends to be antipathetic to flexibility. The critics warn further that responsiveness in value terms should not become relativism, an automatic acceptance of local actors' stated values, which would abrogate moral responsibility (Shadish et al., 1991). They note too that not all case studies are responsive to client needs, neither are all client-responsive studies centred on individual cases. Thus Shadish et al.'s authoritative text on evaluation theory judges (ibid.: 313) that Stake's call for pre-eminent use of case study methods in evaluation only holds good when:

(1) The evaluator wants bandwidth rather than fidelity.

(2) Few if any questions are known ahead of time to be interesting.

${ }^{6}$ See e.g.. Stake (1967, 1995), Richards (1985), Pfund \& Dietz (1988), Padaki (1995). 
(3) The evaluation is primarily going to be used by readers who cannot experience the program themselves and who want extensive contextual information to help decide how relevant that local site is to their own.

(4) The evaluator can forgo higher-quality answers to specific questions that might be yielded by other methods.

(5) A succint summary of evaluation results is not a high priority.

(6) Succint generalizations across sites are also not needed.

(7) Case studies will be seen as sufficiently credible to the client.

(8) Discovery is a higher priority than confirmation.

As evaluators, Shadish et al. go beyond those quality criteria traditional in writings on research methods. They emphasize use and users of a study (see points 3,5 , 6 and 7 above): a good study must be relevant and credible as well as valid and reliable. Arguably, to be relevant in the case's own setting it should probably cover major parties; e.g. it should study interveners as well as those acted on, though the strong tend to be camera-shy. To be relevant in wider contexts, to have a wider point, case studies must have good luck or work in symbiosis with theorizing.

These points are weighty, but Stake's position involves use of further criteria still. He remarks that even if case studies are weak on generating law-like explanations they are strong 'When the aims are understanding, extension of experience, and increase in conviction in that which is known' (1978:7, emphasis added; 'understanding' refers here to grasping participants' interpretations, motives and actions). All three roles are vital in ethics, as we will see.

In a review of some 1980s literature on or relevant to the ethics of development aid, I suggested that 'some readers may well feel, at least on first examination, that the most rewarding pieces outlined earlier were those -- such as the books by Shawcross [a journalist; "The Quality of Mercy", on relief to Cambodia in 1979-83] and HarrellBond [an anthropologist; "Imposing Aid", on aid for Ugandan refugees in Sudan in 1980-85] -- not written by philosophers or economists ! .... For any theory is inevitably simplified and has implicit assumptions and limits to its relevance. Experience tests the conceptions' adequacy and helps reveal what they omit' (Gasper, 1997: 40-41, rearranged). Often far richer experience is drawn on in the studies which are not by phi 
losophers or economists: 'From the urgency of the events it describes, much of the literature from cases like Ethiopia, Cambodia and Rwanda has been pointed and holistic; not formal examinations of dense but narrow data, but thought-provoking accounts of decision-making done with poor information and under pressure' (ibid.:39).

A thick case study is holistic and includes distinctive, even idiosyncratic, situations and details, people and cultures, and treats them in contexts, technical and institutional, local and beyond. ${ }^{7}$ This is characteristically but not exclusively anthropological. For Nyamwaya (1997:198) anthropology's 'holistic approach' means it 'seeks to explain human thought, organization and behaviour within the broader context of socioeconomic conditions', and, we might add, vice versa. Similarly for Pottier, anthropology seeks 'to provide context and ask epistemological questions... holism and reflexivity, the familiar roles that give the anthropologist a distinctive voice' (Pottier, 1997: 219, 223). 'Actors and opinions...need situating' - true also when considering social scientists and philosophers - 'the task of finding out "who's who?" in terms of access to knowledge and power' (ibid.: 221).

The best thick case studies are not necessarily the most detailed. Those sometimes provide merely the raw materials for a good -- enlightening, connectionsrevealing -- study. Lisa Peattie's streamlined 'Planning - Rethinking Ciudad Guyana', about the planning and growth of a new city in Venezuela from the 1960s to the 1980s, is at least as useful as the more congested project histories in Doug Porter et al.'s 'Development in Practice' (on an Australian aided resettlement project in Kenya, 1973-89), or Norman Uphoff's 'Learning from Gal Oya' (on a decade of irrigation organizations on a scheme in Sri Lanka). But each is of exceptional quality, drawing extra insights from its multidisciplinarity and greater spread of years than in most evaluations. (See Gasper, 1994b, on Porter et al.) Many historians would argue that since selections are inevitable they should be explicit, systematic and purposeful (see e.g. Carr, 1961;

\footnotetext{
${ }^{7}$ Criteria for 'thickness' are thus: first, breadth of scope, not necessarily by coverage of many situations but rather the 'situating' of a case, contextualizing it, viewing it holistically; second, degree of detail, notably case-specific, person-specific detail; and third, more penumbrally, use of a plurality of methods, perspectives and even voices. Thickness does not require great length. Gardner (1997) manages to convey all of these aspects in a relatively short paper from a short visit, though the thickness of her study remains limited by the social science conventions and compulsions of anonymity (even of the country concerned) and of paying limited attention to specified individuals in published material.
} 
Stretton, 1969). There should be a guiding set of questions and ideas (though indeed not only or necessarily the ones with which the historian began) which turn an account into a meaningful case, a study, of something, not a doomed effort to recount everything.

\section{Thin case studies}

Many studies which have sufficient depth and investigative character for the ti 
tle 'case study' yet use a rather limited and pre-set range of questions and methods, and hence may be called 'thin'. They are not holistic. When well-done they can be extremely incisive and helpful; for example the studies in Sen's 'Poverty and Famines', of the famines in 1940s Bengal and 1970s Bangladesh, Ethiopia, and the Sahel.

What makes a thin case study 'well-done', productive? Let us examine a number of other pieces, seeking suggestions. Martha Nussbaum and Jonathan Glover's collection 'Women, Culture, and Development' (1995) opens with a case study by Marty Chen that presents the obstacles to obtaining paid employment which have been faced by many rural women in northern parts of the Indian subcontinent: notably disapproval and obstruction by their (extended) families and dominant sections in local 'communities'. A digest of other work, including her own, this thin case study has only one consistently heard voice, Chen's. Further, it focuses only on simpler situations, where women actively seek external employment and yet are hindered and obstructed; but these situations remain real and important since formal employment affects much else. The study informs and enriches several subsequent chapters which take Sen's or Nussbaum's capabilities theory and Chen's case study as reference points.

Many of Robert Chambers's cases in his 'Whose Reality Counts'? appear rather as anecdotes, brief illustrations of a pre-formed conclusion. But some are quite extensive and analytical, draw on work by many others, and might be placed here: notably his cases of 'massive error' and failure to learn from experience, which concern three myths of the 1980s: huge post-harvest losses, catastrophic deforestation by local populations, and successes (somewhere) with animal-drawn tool-carriers.

Using a text based approach, Keith Tester's 'Moral Culture' (1997) looks at reactions to, and subjective involvements in, various mid and late 20th century massacres and genocides. His only case study in my sense is of My Lai, where American troops shot dead at least 347 Vietnamese villagers -- virtually all of them old, women, or children -- in a few minutes one morning in 1968. Here Tester mainly applies a theory rather than examines in personal detail the Americans and the villagers. Like Chambers, Chen, and Sen on famines (e.g. in his discussion of 1840s Ireland), Tester piggybacks effectively on previous work on his case; and then usefully connects it to related 
broader theorizing (from Peter Berger, Nietzsche, Freud, Durkheim, Weber, and Hannah Arendt). ${ }^{8}$

An effective thin case-study might thus be one which builds on previous thicker work on the case, whether by the author or others, and starts to identify or posit key aspects and relate the case seriously to other instances and to relevant theory. The intention can be to illuminate and/or draw conclusions about the case, or to try to identify principles possibly relevant to a range of cases. Part of the clarifying and assessing of any posited principles might require a move to a different, more abstracted, mode, as we discuss later.

\section{Real-life choice situations - with or without advice}

Some discussion cases are presented in more or less neutral fashion, giving a situation and a choice arising, followed by a specific request for the reader to make and argue her own choice and/or by presentation of an argued choice by the author. Such choice situations can be written thickly or thinly. Usually they are towards the thin side, as in many public and business administration exercises, since the intention may be to ensure space for interpretation, argumentation, and mobilization of readers' own experience and insights. Scenarios used for instruction or learning in other professional fields - or in religion -- often share this style: a brief non-committal outline of a complex choice situation, to force the audience to think; usually followed by a suggested response by the author/teacher.

In his lucid and helpful 'Doing the Right Thing - Relief Agencies, Moral Dilemmas and Moral Responsibility in Political Emergencies and War', Hugo Slim presents four 'case studies' (Slim 1997a). He also entitles them 'scenarios', which fits my usages better, for the cases while real are very schematic. Each is stated in about 200300 words, to describe a choice that has faced relief agencies. Slim then expounds in about 500-800 words for each his recommended responses. The scenarios have this

\footnotetext{
${ }^{8}$ On a lesser scale, in a paper on 'Equity, Equality and Appropriate Distribution' I analysed a series of cases to check and illustrate how far categories for talking about distributive justice, derived from Blanchard (1987) and Sen (1984), could illuminate policy debates in Africa on positive discrimination, landuse reform, land-title reform, and so on. Building on available case descriptions by others or myself, and
} 
concern: how far should one 'dine with the devil' -- what ethical compromises are acceptable -- when trying to do good?

Let us look at the first scenario. It asks whether relief agencies should have supplied the Rwandese refugee camps in Zaire in 1994-96, despite knowing that the camps not only contained but were dominated by Hutu forces who had been involved in the preceding genocide of Tutsis (and of Hutus willing to work with Tutsis to implement the 1993 Arusha peace agreement), and who were actively continuing in armed conflict in Rwanda and preparing for a violent return there to complete the genocide. (Further, not mentioned by Slim but known amongst some agencies, the Hutu forces also continued with killings in the camps and environs.)

Slim argues that any future mis-deeds by Hutu forces coming from the camps would be their own responsibility, not those of agencies who had supplied them with non-military material; the responsibility of relief agencies is instead to supply food and other necessities to people in distress. He appears to advocate this even if the agencies were certain or near certain that the Hutu forces would return to genocidal activities. In contrast he holds that the United Nations and member states were culpable for not taking steps to prevent possible recurrence of the 1994 Rwanda massacres and instead 'allowing a genocidal regime to remain in power over people, so leaving it free to make the kind of moral choices which could pursue violence once again' (sic., p.13). Because of the specific commitments made in their charters and the conventions they have signed, they are held culpable for not acting against foreseeable genocide whereas relief agencies are not. Many relief agencies however nowadays also specify their mission as furthering peace and human rights, besides feeding the hungry.

Slim presents difficult choices, different responses, and his own argued recommendations. He does not discuss the cases with a depth or tone intended to further other interpretations and recommendations. The relief community and some of its agencies and their members were torn apart by the stress of choices faced in Rwanda, Zaire, Sudan, Bosnia and elsewhere. One role of his scenarios seems to be to strengthen morale, provide simple workable guidelines, help staff sleep at night. He uses the format of the sermon, and subordinates case detail to moral theory. However, he gives sufficient 
materials to provoke reflection and possible alternative responses. The cases serve not only as unanswerable anecdotes. ${ }^{9}$

De Graaf's Tanzania bilharzia story at the beginning of this paper is another case of a real choice, this time a case with a more anecdotal personal element. It lacks detail, but was used by him to invite advice and stimulate thought rather than to demonstrate and endorse a particular perspective. In fact the very lack of detail lets it serve as a sort of Rohrsach test for drawing out people's presumptions. Before taking a stance should one not know something about the nature of bilharzia and its effects in the specific locality concerned, the treatment given by traditional doctors to those children who in fact do not have bilharzia, its effects, and the range of other possible treatments? ${ }^{10}$ Yet sometimes, as at the conference where de Graaf presented the case, battle lines are firmly drawn in advance and cases serve to re-run old conflict scripts rather than to test their premises and applicability.

\section{Real-life anecdotes and other illustrations}

Cooper and Packard note that: 'Template mechanisms are preconstructed frameworks which are used to simplify and control complex environments. One such mechanism is the "case", reducing a complex instance to a single useful message' (1997:24). Within organizations, many real cases are reduced to simple warning plaques: 'Remember the case of [Munich 1938 / Rwanda 1994 / ...'. Given that there are richer types of case, this reduced notion of a 'case' matches what we will call anecdotes.

Anecdotes are typically superficial and relatively short stories that serve to illustrate a point. They lack the more exploratory investigative character and usually also the depth of the case-study proper. Frequently the point is pre-selected. Robert

\footnotetext{
${ }^{9}$ For a critical discussion of Slim's cases and the idea of narrower bounds of responsibility and accountability for aid and relief agencies, see Gasper (1999a).

${ }^{10}$ Bilharzia particularly affects children of a certain age because it is contracted by bathing and drinking in infected rivers. Younger children are less exposed; older children in general acquire resistance and hence stop passing blood. Treatments can include -- when funds and supplies permit -- drugs, or elimination of the freshwater snails that carry the larvae of the bilharzia worms, or elimination of carriers outside water like rats; or change in patterns of bathing and drinking if alternatives are possible and acceptable.
} 
Nozick's example of the riches accruing to a famous sportsman through voluntary, gladly made, 
payments by myriad fans asserts the unquestionable rightness of the idol's immense wealth and his/her uninfringeable claim to it all. He does not probe real cases in further depth. ${ }^{11}$ Closed rather than open use of a case is common; for example, most of the cases in Caufield's disturbing history of the World Bank or in Chambers' 'Whose Reality Counts?'. This is not necessarily a criticism: Caufield's and Chambers's illustrations seem powerful and convincing. And sometimes anecdotes serve as vectors of insights on new situations. However, many cases Chambers describes involve the use by others of anecdotes and illustrations to simply re-endorse a misguided pre-fixed position. Fairhead and Leach (1997) give a fuller exposition of one example, the 'evidence' claimed for progressive deforestation in Guinea even when masses of villagers and photographs indicated the opposite.

Anecdotes also frequently function as put-downs, illustrations ('if yet more were needed') of the absurdity, sub-humanity, and otherness of 'them'. Such anecdotes flourish in everyday talk, lowgrade journalism, and simple minded or abusive travelogue. Talented exponents of the abusive variety have included Evelyn Waugh, Paul Theroux and the Naipauls -- though V.S. Naipaul has later appeared too as a practitioner of thick-ish life-story social history (Naipaul, 1990). ${ }^{12}$ The anecdote is a natural partner of international aid and the quick visits and existential distances common in 'technical assistance'. Leonard Frank's 'The Development Game', a short story about an anomic multi-national UN project identification mission in the frontier province of Pakistan, is itself an extended, depressing, anecdote. Though fictional it apparently derives closely from experience. Aid anecdotes from 'Left' and 'Right' can be indistinguishable; for example Posthumus's tale (1997:24) of how quantities of copper wire given to a Zimbabwean village for a lightning conductor quickly reappeared as bangles.

\footnotetext{
${ }^{11}$ Nozick refers to a real person but without examination of societal and historical context. While a fictional example could have been used for his purpose, the reference to not merely a real celebrity.but a historically unique, sympathetic figure -- Wilt Chamberlain, perhaps the first black American basketball super-star - adds a special pitch to his attempt to mobilise assent for an absolute right to retain all of whatever one receives by legal means in the market (see Gasper, 1986).

12 On the Naipauls, see 'The Not So Gentle Art of the Development Anecdote' in Gasper (1986), which disputes not "whether the Naipauls offer particular insights but the quality of their involvement and hence of their overall understanding and impact. [Their] Anecdotes--inevitably fragmentary--about individuals lead into judgements about nations plus proferred development prescriptions' (pp.180-1).
} 


\section{Conceivably true fictions}

Anecdotes dispense with information about situations when it is incidental or inconvenient for their message. Armchair philosophy has tended to dispense with real situations altogether, finding them inconvenient for analysis, clumsy, too complicated. It prefers fictions -- some of them conceivably true, others conceivable but impossible - so that it can focus precisely on one or two issues. This artificial style has thriven in analytic philosophy, with a predominant contemporary Anglo-American middle-class range of references and cast of characters. Any problem lies not in the honing of concepts and generation of issues, but rather if and when such work seeks to draw conclusions in advance of exposing its constructs to real and more varied experiences.

Let us not forget that fiction (hopefully in realist mode) forms an essential part of all appraisal and evaluation: the specification of a counter-factual case concerning what would happen or would have happened without the intervention that is under assessment. However well we try to simulate this case, through experiments or whatever else, there remain matters of judgement in deciding that a comparison case sufficiently represents a situation exactly the same except for the influence of the intervention (see e.g. Deming, 1975). ${ }^{13}$ Comparison cases always differ from the intervention case in various ways other than not having had the intervention, so we require a supportive story to justify our taking them as good enough representatives of the fictional, counterfactual case.

Hypothetical, but possible, cases of other types figure importantly in ethics. Their force typically rests on being possible, for their role is to make people consider their own predictable feelings in or about cases which they can vividly envisage and thus 'feel themselves into'. Much of Martha Nussbaum's work tries to enrich ethics and social philosophy from examination of fiction (e.g. Nussbaum, 1997). We can look at two sets of more schematic examples.

\footnotetext{
${ }^{13}$ Impossible, or implausible, visions of project performance might also figure, as inspirational and legitimating 'myths', to call forth effort and support for enterprises with uncertain and delayed benefits. Such visions come closer to the category 'impossible fictions'.
} 
First, the American philosopher Thomas Nagel (1987) contends that ethical arguments are not based on only self-interest (though self-interest can often be concluded 
to be ethically valid), nor on appeal to authority (e.g. religious). Those are different types of arguments for behaviour. A distinctively ethical approach is seen if one reviews one's own opinions, arguments and feelings about fairness in respect to oneself, and then draws out the implications for one's relations with others. For example, if your umbrella has been stolen at a restaurant, you would probably feel resentment not just annoyance, and that nobody should do that to anyone else. Therefore, says Nagel, you can (if not a very small child or psychologically damaged) be led to see that you should not do the same to any one else (Nagel, p.158). This is the line of reflection: 'How would $I$ feel if you/they did that to me?'.

Note also a partner line of argument, thinking about how others would feel in the same situation that you would resent: 'How would they feel if you/I did that to them?'. This thinking about others' reactions may alter one's own feelings about the action; and then one tries to make one's whole set of beliefs consistent. In both lines of argument people are asked to think about other cases, examine their feelings, and then review their other opinions to establish consistency. Nagel's examples remain from somewhat restricted milieux but are legitimate and effective for his main audience (another example is: should one steal a library book, for one's 'important' work?); and the lines of argument can readily fit development intervention cases.

Secondly, in the following example from development policy debate I sketched some hypothetical cases of consent, with in some instances possible real counterparts.

[Consider] some cases where women accept subordinate roles. Case 1: they have no real alternative; so their acceptance does not satisfy [Onora O'Neill's conditions for what should be acceptable to others as being a person's choice: including that the choice was under conditions of no deceit, no fear of victimization, adequate awareness, and ability by all to reject or renegotiate]. Case 2: they have real alternatives, but without adequate education or sufficient awareness and information about the alternatives; this too fails to meet the requirements. [Li (1995) argued for example that women in contemporary China had had little opportunity to be exposed to, or systematically assess, or hold, conceptions of female roles alternative to that propounded by State and Party.] Case 3: they have real alternatives, thorough awareness, and no cultural and psychic moulding into accepting subordinate roles; their acceptance of subordinate roles is then fully valid in terms of AC [acceptable consent] principles even if unexpected. Case 3 could have as variants: (i) the women have never been moulded into any roles -- but that is absurd; or (ii) they have been de-moulded, by education and reflection, but accept one or more argument given for their subordinate role -- this is not absurd, but still of questionable realism for most women.

More prevalent may be Case 4: the women have real alternatives and reasonable awareness of them, but are culturally and psychically moulded into accepting, and perhaps relishing, (mainly) subordinate roles. The reports cited 
earlier from Kerala [in Gasper, 1996] might describe such a case for a majority of women. The $\mathrm{AC}$ rules do not object to the acceptance, only require that women continually have the alternatives and (access to) a good awareness of them -- even if these two conditions go against the local culture. If such an awareness generates dissatisfaction by women with their culturally given roles, then it is no longer our Case 4, and [O'Neill's] AC rules would imply that the roles are not just. (Gasper, 1996: 654-5)

All the cases are presented in hypothetical form, though real counterparts are posited for Cases 2 and 4, and real examples can certainly be found for Cases 1 and 3(ii). Case 3(i) is dismissed as inconsistent with firm knowledge (that those not moulded within a society remain sub-human, like 'wolf-children'). This type of argumentation in hypothetical mode thus relies on existing or future empirical knowledge from other contexts. Not all argumentation of the hypothetical type ('imagine a case in which...') is restricted in this way; some draws insights from cases which we believe impossible.

Impossible fictions

O’Neill was led to consider which hypothetical cases are relevant, from reflection on the approach of John Rawls. Rawls's 'original position' and its 'veil of ignorance' provide the classic modern examples of influential, impossible fictions in philosophical ethics. In the 'original position' all protagonists know (amongst other things) the range of possible outcome positions for individuals that corresponds to each possible set of rules for their society, but not which positions they personally would occupy. They are then required to agree a set of rules. Protagonists are expected to be riskaverse, personal-utility maximizers, and hence to adopt a maximin strategy and agree on rules that will do best for the bottom group in the society. Amongst numerous objections raised against Rawls, many objected to this notional situation, arguing that it did not and cannot exist, people cannot shed their identities and it is farcical to premise that they should; and so on.

One cannot merely object that Rawls considers a case that cannot exist: philosophers have always used this method. Nussbaum for example presents classical Greek analyses of human-ness, which compare humans with notional beings who lack some of our attributes (e.g. lack mortality, as a god), in order to draw out just what are our attributes and their implications. Any objection would have to concern the particular nature of Rawls's assumptions, relative to the purpose of his analysis. (We will see 
some such claims later, in Section 3.). O'Neill agrees with the necessity and desirability of abstraction -- ignoring some features of people's positions -- but stresses that it can be done unacceptably, ignoring vital relevant features about the agents involved and/or making excessive presumptions about them (e.g., perhaps, that they are only riskaverse, selfish maximizers). Jamieson (1991) adds warnings about sciencefiction/fantasy cases in moral philosophy. Any reactions we give to particular proposed implications of the posited differences (of technology, laws of nature or whatever) will not be reliable, because we will not know enough about their other implications for a whole way of life. In contrast, in imagined but possible cases we know by experience enough about the context to provide worthwhile reactions.

In discussing impossible fictions have we gone beyond an immediate domain, of ethically puzzling cases in or about development practice in which people ask: which other cases are relevant to compare with, and which principles should we use to help think about our choices? Have we entered the domain of cases used in philosophical theorizing to try to construct and choose between moral principles? If so, that is not a problem -- this paper aims to clarify the range of types of case we encounter. Rather it provides instructive contrast, helping us to perceive some types and uses of case more sharply by comparison with others. But further, there is no tidy gap in ethics between theorizing and the examination of cases. Argument about disputed real cases rapidly takes us into theorizing, and not only when the argumentation is by philosophers. 'In real life it is common for people to apply role reversal tests, to appeal to possible outcomes of actions or policies, or to point to special responsibilities and obligations... When we ask why we should be moved by such considerations, or we test them in order to see whether they hang together with other beliefs and commitments that we have, we are engaging in moral theorizing. Generally we are pushed into theorizing by pragmatic considerations... [The] distinction between moral theorizing and moral practice is an untenable dualism. Moral theorizing is part of moral practice.' (Jamieson, 1991: 479). Any one familiar with current debate on the ethics of humanitarian relief, for example, will recognise this. In disputes about burning current or recent cases, practitioners and policy-makers (not only philosophers) bring forth general principles and offer arguments for them, including reference back to earlier cases and to hypothetical situations. 
I called Rawls's 'original position' a hypothetical case (an imagined not a real instance) which also happens to be impossible. If we feel uncomfortable at calling it a 'case' at all we can equally call it an impossible hypothetical 'situation'. More significant than choice of label is that interesting insights about ethical choices can be drawn from such thought-experiments. Improvement of the labels might still help, so we look at that next.

\section{Refinement of the classification?}

The classification used above -- six types of 'case', real or imagined -- is certainly imperfect. ${ }^{14}$ I will not attempt a perfect one, probably none exists. Yet having now given some feel for a range of relevant case/example types, tidying and deepening of the classification can reduce the danger that the quality, communication and use of any insights will be undermined by readily remediable gaps and obscurities.

The classification has concentrated on two dimensions of variation: (i) thickness-thinness, and (ii) real-imagined. The table below summarizes the six types of recourse to cases that we examined, using the same numbering system with a little elaboration especially for the imaginary cases. Thus it employs within the imaginary cases the further dimension: (iii) possible versus impossible.

\footnotetext{
${ }^{14}$ It is more refined than the classification in Jamieson's survey article on method in moral philosophy (1991), which modified O'Neill (1986) and cites four types of example used in moral theorizing: (a) 'literary', i.e. taken from fictional writings; (b) 'ostensive', i.e. taken from real life; (c) 'hypothetical', i.e. situations or events that are possible but have not occurred; (d) 'imaginary', i.e. situations that are as
} 


\begin{tabular}{|c|c|c|c|}
\hline & THICK & INTERMEDIATE & THIN \\
\hline REAL & $\begin{array}{l}1 \text { The anthropological } \\
\text { case study } \\
\text { 4b Thick anecdotal } \\
\text { accounts }\end{array}$ & $\begin{array}{l}2 \text { The thinner real case } \\
\text { study } \\
3 \text { The thinner real choice } \\
\text { situation, with choices } \\
\text { highlighted and kept } \\
\text { separate from advice }\end{array}$ & $\begin{array}{l}\text { 4a Thin anecdotes from real } \\
\text { life }\end{array}$ \\
\hline IMAGINED & $\begin{array}{l}\text { 5a Conceivably true thick } \\
\text { fictions } \\
\text { 6a Impossible imagined } \\
\text { thick stories \& } \\
\text { situations } \\
\end{array}$ & $\begin{array}{l}\text { 5b Conceivably true thinner } \\
\text { stories or situations } \\
\text { 6b Impossible imagined } \\
\text { thinner tales \& } \\
\text { situations } \\
\end{array}$ & $\begin{array}{l}\text { 5c Conceivably true but } \\
\text { fabricated thin } \\
\text { anecdotes } \\
\text { 6c Impossible imagined } \\
\text { fragmentary aspects }\end{array}$ \\
\hline
\end{tabular}

A number of other dimensions emerged: (iv) open-minded/inquiring versus closed / concerned only to convey a set conclusion; (v) evaluative criteria and judgements in-built or as far as possible separate and explicit; (vi) evaluative conclusions/advice provided or not. Criterion (iv) was used to distinguish 'case studies' from anecdotes. Anecdotes were also taken to be typically thinner, but not necessarily so; we might have long thick anecdotes or series of anecdotes. Similarly, one can have thick, but closed, case studies, as in some historiography and autobiography.

Highlighting these dimensions, and no doubt there are more, helps us to see additional possibilities beyond the six discussed. For example, in the 'thin' column we could add: real, thin, statistics; real, solitary, visual images; and fabricated images. Much has been said about the use and abuse of images and statistics in development interventions and North-South relations. De Waal (1997) makes a fierce assault on practices by Northern media and NGOs with respect to famines in Africa, real or feared.

If we add a time dimension we can distinguish 'snapshot' cases from those that extend over time with a story-line. Stories are the characteristic mode for understanding interrelations of specific people who think, feel and choose in complex ways. Emery Roe writes on the disturbingly simple story structures underlying much development planning (e.g. Roe, 1989).

far as we know impossible. All 'literary' examples fall into one of types (c) and (d) or sometimes a thinly disguised (b), so this reduces to three types, with my first four categories all covered by (b). 
Thick-thin, open-closed, and possible-impossible constitute dimensions of contrast, not binary pairs; likewise the divisions between descriptive cases and 'choice situations' and between explicit and immanent values. Further, a plurality of criteria which can move independently of each other, as mentioned for 'thickness', means that we have a set including many 'grey' intermediate possibilities. We might be led beyond the 'thick-thin' contrast and seek a more complex set of categories. Similarly interesting could be to specify constituent units of cases (like elements of a story), their interrelations, and see if and how they vary across the six types mentioned here.

Such extensions are unnecessary for the purposes of this paper: to show that there is a range of significant types of case each with strengths, limitations and a distinct role or roles in normative argumentation and practice. Having established the presence of a range, the second half of the paper gives further attention to strengths, limitations and roles, in particular through closer examination of the thick-thin dimension.

\section{3. 'THICK' VERSUS 'THIN': WHAT MAKES CASES RELEVANT, AND FOR WHAT?}

In Section 3 we consider the complementary virtues of including a lot (being thick) if it really is relevant, and of leaving out the less important (being thin) if it really is irrelevant, in discourse oriented to making or assisting ethically charged choices. We will see how partly competing philosophies lead to the choice of thicker or thinner cases, but also note scope for coexistence since relevance depends on purposes. Different purposes for different occasions will justify different styles. No attempt is made to prescribe a single model.

We look first at the roles of and types of insight from concrete examples, especially detailed, holistic, contextualized examples or case studies which manage to offer vicarious experience. A longer case illustration, from Arne Olav Øyhus (1998), will underline functions of relatively thick case accounts. But while thick description can provide instructive and even inspiring exemplars, there are misunderstandings about its power and priority in moral argument. Out of presumptions of harmony and consensus comes a communitarian claim that moral choices within societies can and should be settled by detailed description of 'the culture'. This questionable approach will be con 
trasted with ideas from Onora O'Neill about the essential role of well-selected exclusions in ethical argumentation: vital features must not be left out but nor must irrelevant ones be included. And since ethics have to be more than an intellectual exercise alone, we consider the role of thick moral exemplar cases in strengthening motivation as well as providing understanding. Section 4 will then integrate these ideas into a more explicit picture of linked stages in work in ethics.

The importance of being concrete and of being thick? - I: exemplars and vicarious experience

What, within broader arguments, do cases do and examples exemplify, and how? They convey patterns; thick cases can also provide vicarious experience. As Thomas Kuhn emphasized (1977), an exemplar is a specific instance which embodies and illustrates ideas that are not easily or satisfactorily formalizable.

This exemplar is and remains a particular that in its very particularity reveals the generality that otherwise could not be defined. Courage is like Achilles... The example is the particular that contains in itself, or is supposed to contain, a concept or a general rule. (Arendt, 1982: 77, 84; cited by Tester, 1997:55.)

For Kuhn this was the prime meaning of the term 'paradigm': a concrete model of (in his case, scientific) practice which conveys ideas such as how to 'see' a situation and decide which formalization should be applied to it and how, and about how to foresee and avoid various pitfalls. Although 'paradigm' originally means exemplar, a second sense used by Kuhn unfortunately crowded out the original and more profound sense, to Kuhn's own regret. This second sense was paradigm as disciplinary matrix: the set of basic commitments (including notably the set of approved exemplars), shared by a group of scientists. Why is the exemplar sense more profound? Because exemplary instances are many and multi-faceted, and because the definitions and rules and advice which we impute from them are more subtle and fluid (yet exist, contrary to philosophers who take a radically particularist line). Their advice on patterns is absorbed sub-consciously so we can apply it without delay for conscious reflection; and it comes embodied in a vivid real example that aids recall. We learn our first language and are in large part trained in 'disciplines' and professions in just this manner.

In sciences and professions the exemplars from which we learn include tales of exemplary good/bad/typical practice. These are a major way in which we absorb skills 
and values. Story exemplars can bring associated emotions that also enter the memory and help to provoke action. Benner itemizes and illustrates types of 'learning narrative' in the caring professions, based on her interviews with nurses: 1. Stories that show the importance of remaining open to experience and not prejudging cases; 2. Stories that convey how to better judge degrees of involvement with patients and families; 3. Stories that reveal the limits to our understanding and control: 'narratives of disillusionment'; 4. Stories about coping with suffering and death; 5. Stories about dealing with colleagues, systems and cultures (such as arrogant doctors, male chauvinists, biases against showing concern, etc.). ${ }^{15}$ Each area of practice has its own sorts of stories. Far from all such exemplars are strongly culturally relative. The same applies for exemplars of another sort or in another role, which we discuss later: those that provide ethical inspiration not only practical advice.

Practice stories and inspirational exemplars are typically not just concrete but thickly textured too, and work by providing vicarious experience.

\footnotetext{
Direct personal experience is an efficient, comprehensive and satisfying way of creating understanding, but a way not usually available to our evaluation-report audiences. The best substitute for direct experience probably is vicarious experience--increasingly better when the evaluator uses "attending" and "conceptualizing" styles similar to those which members of the audience use. (Stake, 1980:83; emphases added).
}

New understandings, explicit and tacit, contribute also to new behaviour, the intention of ethics and policy analysis. Vicariousness helps here via 'adding to one's experience and re-examining problems and possible solutions intuitively.... [We recommend that] program evaluation studies should be planned and carried out in such a way as to provide a maximum of vicarious experience to the readers who may then intuitively combine this with their previous experiences' (Stake \& Trumbull, 1982:2). This intuitive re-examination and revision works because so much of our thinking is in terms of tacit and evolving patterns, not explicit rules.

One rare example of a case-study by a social scientist which is rich enough to convey besides 'thickness' -- a sense of a whole context and real lives -- a vicarious

\footnotetext{
${ }^{15}$ See also Forester (1993) on 'practice stories' in urban planning. 'Narratives' connotes relatively high structure, linearity, cohesion; 'stories' here suggests something looser, raw material for narratives (Sivaramakrishnan \& Agrawal, 1998:35).
} 
feeling of having met particular individuals, been in specific locales, observed actual meetings, is - surprisingly -- by a development economist, Robert Klitgaard's 'Tropical Gangsters'. Klitgaard's account of his work in the late 1980s as an advisor in Equatorial Guinea is partly autobiographical: it describes real people and places, not only themes. ${ }^{16}$ Further, his style is novelistic, even if a thinned-down man-abroad Hemingwayesque style: he relies on directly reported speech not only on paraphrases, and he treats aspects of individuals, occasions and routines that do not enter even most anthropologists' reports. The style conveys a sense of engagement with people as people, rather than as imperfect embodiments of social science categories or as (un)friendly aliens. And it is integral not incidental to his argument, which is that an effective economic programme can stem only from locally based (not Washington based) analysis, commitment and 'ownership'; that to externally facilitate and strengthen these requires a collegial interaction, which in turn requires from facilitators a combination of courtesy, curiosity, openness, and vivacity -- in each case both intellectual and interpersonal -- and thus a capacity and desire to deal with others as people, not just as counterparts or clients or other. ${ }^{17}$

De Waal's 'Famine Crimes' recounts a comparable example: the extreme contrast in style between Mohamed Sahnoun, the UN special representative in Somalia in 1992, and his successor Ismat Kittani. Sahnoun argued against and was building alternatives to the disastrous US-led UN-mandated military intervention which Kittani then helped to precipitate and administer. While unusually pointed in giving attention to individual officials and their styles, de Waal's brief treatment remains anecdotal and

\footnotetext{
${ }^{16}$ The names in Tropical Gangsters are usually amended, but in general the persons will be recognizable to others who work or have worked in the same organizations. They are not composite characters, unlike the key figure of a 'devil's advocate' entitled The Reasonable Social Scientist in Howard Richards's The Evaluation of Cultural Action, another study concerned to provide vicarious experience. It describes a community development program in Chile and Richards's experience in evaluating it. Seeking to change specific methodologies not only a mind-set, Richards aims to persuade primarily through general arguments which are given extensive illustration, rather than primarily through Klitgaard's approach of conveying lessons through a story.

${ }^{17}$ Not only are these requirements for effective facilitation high--so that one may doubt how widely they can be attained and sustained--facilitation is not a substitute for structural changes, in institutions, capacities, and so on. Klitgaard would agree, yet stress the potential--and duty--for well-directed and wellhandled facilitation to contribute towards such changes. See Gasper (1999c) for further discussion.
} 
more forgettable, without the 'bite' that the details and intimacy of vicarious experience 
can give. $^{18}$

Klitgaard's case study matches an expectation that vicarious experience is usually best obtained through an intermediate level of thickness. The precise level depends on the audience, but great thickness (in using the style of those being described) may well be impenetrable to the audience, whereas thinness can fail to establish credibility and empathy.

Vicarious experience is important within as well as across cultures, as suggested earlier by Nagel's (artificial) examples. For cultures are not well-defined, clearly separate, unities that exist fully programmed in 'their' members' minds. Vicarious experience across cultures tends to be thinner; but some examples seem to transcend boundaries. Let us take a longer case.

\section{Øyhus on the ethics of transfer of ox-cultivation to the Toposa}

The Toposa are a small group of semi-nomadic pastoralists in Eastern Equatoria, Southern Sudan. The men herd cattle, either their own or if they are poor someone else's, and live in camps a few days walk from more central settlements where women, children and the elderly spend most of their time. The women cultivate sorghums around these settlements, but most move to the camps in the dry season, when cattle products become the main food. Cattle have belonged in men's world, farming in women's, except that in livestock-poor families men may also contribute in farming. Technology was at the level of hoe cultivation, so yields were low despite use of fertile (but heavy - mostly Black Cotton) soils. Enormous disparities in wealth are present: some people own huge herds, some little or none. From around the mid-1960s rainfall became more erratic and on average lower. Together with the introduction of automatic guns, this brought escalation of the traditional cattle-raiding between the Toposa and other groups such as the Turkana and Dinka, to such a degree that it is now 'quite

\footnotetext{
${ }^{18}$ Randall Baker's praised Laughter and Tears after Communism, his diary of a summer as a Fulbright scholar helping design a new programme at an independent university in Bulgaria, suggests some similar lessons to those from Tropical Gangsters, but is constrained by its raw materials: a three month trip in a marginal role to a country whose language the author did not speak. It stays at the levels of paraphrased
} 
speech, 'characters' in the narrower sense, and extended, serial, anecdote. The proposed lessons do not emerge primarily out of its reported events. 
similar to regular warfare' (Øyhus, 1998:10). By the late 1970s substantial numbers of Toposa had lost their animals due to drought, disease or raiding, and serious malnutrition was widespread.

In the early 1970s, at the end of one civil war in Sudan, a Norwegian NGO started relief work in Eastern Equatoria. In the early 1980s it began work with the Toposa in response 'to the famine situation in the area' (p.6), and decided to promote quick maturing grains, root crops, and ploughing with oxen. However it was aware that 'oxen were "sacred" for the Toposa men' (p.13). Therefore the proposed innovation was presented to the local councils of (male) elders, who led series of lengthy discussions. Was ox-cultivation compatible with nyepite kangi Toposa, the Toposa's system of norms, values and beliefs -- especially given that it would be a novelty and yet nyepite is, in Toposa eyes, eternal and unchangeable? After 2-3 months of discussions, the answer was yes. Within the treasures of nyepite, suggests $\varnothing$ yhus, the elders could feel that they had identified ox-cultivation as a dormant practice, approved but not yet used because not previously needed.

$\varnothing$ yhus raises two concerns about this innovation: its legitimacy and its effects. Firstly, 'the new cultural item was accepted by the elders, who, in reality, did not know what they were doing. They were totally ignorant because it was far beyond their capacity to perceive the consequences of applying the technology. It was therefore, in reality, the outside expert who made the decision.' (p.15) This will seem strange to the elders who took the decision, and who, as we will see shortly, were quite capable of saying no. And whether the elders were less able to predict consequences than the outsiders is open to debate. Concerning the likely effects, to emphasise crop-production in this semi-desert savannah shifts the Toposa, $\varnothing$ yhus fears, towards a more vulnerable way of life, for crops fail totally in some years, and intensified settlement and grazing around the cropping centres can both bring erosion and offer a greater target for raiders.

The NGO knew that oxen were part of the male economy, and arable farming part of the female economy. It decided initially that ox-cultivation would be more easily accepted via increasing entry of men to cropping rather than by entry of women to animal husbandry. However as the ox-cultivation programme expanded, the NGO became concerned at the unintended effect of exclusion of women, whom they feared 
would lose their status in farming and their autonomous place. A proposal to let women plough was brought to the councils of elders -- and was clearly rejected, as against nyepite. Amongst the Toposa however, the elders can condemn, shun and shame, but have no power to forbid or prevent those in other families. The NGO decided to offer ploughing training to women. Some came forward from the start, from a Catholic mission station, most of them socially marginal widows and orphans. Later, however, many other Toposa women applied for and received training.

The whole experiment was terminated in 1985 when rebel forces in the new civil war entered the area. The Toposa dispersed to their cattle camps. For the elders, suggests $\varnothing$ yhus, this disaster could be interpreted as the consequence of a break from nyepite inherent in women handling cattle. (Others, we could posit, might claim it as the heavens' reply to introducing ox-cultivation, or to doing so first without women.)

$\varnothing$ yhus's case study does the following, hopefully evident even from this summary at one tenth its length.

- It shows profound value conflicts and corresponding areas for examination and choice.

- It suggests the pervasiveness and centrality of unintended and indirect effects (such as a possible clash arising between elders and women over who 'owns' 'the culture', who defines what it will include). These reflect the interconnection of multiple arenas, beyond the powers of foresight of those present.

- It brings these issues to life, to an extent and with a richness likely to be absent from generalized reference: its review of conditions and events is holistic, contextualizes and provides some culture-specific details, though it lacks individual persons and voices.

- It sows at least some seeds for an answer to 'why should we be concerned?'. Its exposition of the complex adaptations to a difficult environment seen in the Toposa's way of life, the new hardships arising from external forces, the threat of an undeserved decline in women's position, the careful deliberations of the elders (and the NGO), the decision of some women to ignore the elders' ruling, may establish a basis of sympathy and for external response of some sort.

- Like de Graaf's bilharzia case it does not provide an answer for what such a response should be. 
The importance of being thick? II: A communitarian claim

Having been exposed to situations marked by ethical challenges, how far will thick descriptions help one resolve the choices? How, for example, could one pursue this case on oxen ploughing, or the bilharzia case from Tanzania? Intuitions manifestly differ between people. Can we resolve through identifying in more detail the local traditions? -- but these can be interpreted and valued differently by different local residents, and predominantly so by dominant groups, who might for example downgrade the concerns of women and children. Who represents the children whose lives could be in jeopardy in the bilharzia case ${ }^{19}$

Clifford Geertz used the adjective 'thick' for a type of description. We need thick descriptions of cultures and action within cultures because they are subtle, complex, contextual. Michael Walzer's 'Thick and Thin' has taken the term 'thick' instead for a style of moral argumentation which is 'richly referential, culturally resonant, locked into a locally established symbolic system or network of meanings' (1994:xi; my emphasis). A link between the two usages is provided by the idea (though it is not necessarily Walzer's) that moral argument largely or solely reduces to finding the culturally authentic description of an action, which will itself contain or imply an evaluation.

Walzer further holds that moral argument within a society is and should be 'thick'; whereas moral argument between societies is 'thin' ('simply the contrasting term', loc.cit.), derived from the thick domestic discourses by reduction and simplification to find common denominators, and thus relatively weak and limited. He thereby tries to place thick and thin argumentation in context, by reference to when they are used and what they can be useful for. Being thin is not automatically inferior nor being thick automatically superior. But his picture of moral argumentation is in some other respects questionable.

The view that intra-societal moral thinking must work through thick, culturally

\footnotetext{
${ }^{19}$ In Fréderique Apffel Marglin's well-known case-study from colonial India, 'the risk of death from [indigenous] variolation varied from 1 to 3 per 100' (1990:109), significantly higher than for the Western vaccination against whose imposition she protested. Thus her protest had to concern not just imposition itself, but to assert an overriding value of maintaining a (reported) traditional way of life in which variolation was integrated with worship of the goddess Sitala.
} 
specific, descriptions has several limitations. Much intra-societal moral argumentation is thinner. First, thick descriptions and thick exemplars are important in moral thinking, including in conveying complexity and a feel for situations; but not all valuable exemplars require much thickness. Thickness is not always necessary. Secondly, it is not always sufficient. On some occasions finding an agreed thick description of an action suffices to produce a moral judgement, when it then appears 'so unambiguously desirable or deplorable... Yet different examples would show that even the finest-grained agreement on the appropriate articulation and description of cases may leave us uncertain how to act' (O’Neill, 1996:87). This might well apply for Slim's emergency relief cases or the bilharzia case. ${ }^{20}$

Thirdly, in a case like Toposa ox-cultivation we seek a moral description of a new behaviour. There is no existing description. Toposa elders (and whoever else is involved) can argue then in terms of pattern and principles. The elders find attractions in, and no reasons to reject, the innovation. For women's involvement in such cultivation there is again no existing description, and here existing principles conflict: arable farming is women's sphere and cattle are men's sphere. Discussion may bring no agreed description: many Toposa women--not merely NGO outsiders--reject the elders' conclusion that they cannot be involved.

Fourthly, even agreed descriptions can later come to be seen as wrong. While some matters certainly are morally relative, in that there is no best way (sometimes even no better ways), cultural relativism goes too far ('locked in') and understates the importance of thinness, necessary abstraction. In the bilharzia case and the oxploughing case it will defer to local tradition and/or the views of the traditional guardians of the 'locally established symbolic system'. ${ }^{21}$

\footnotetext{
${ }^{20}$ And conversely: 'Reasoning that abstracts from culturally specific, locally intelligible act descriptions can remain intelligible to those from whose daily "thick" descriptions it abstracts. Particularists are simply wrong to think that intelligibility is inevitably threatened by abstraction. All act descriptions, whether thicker or thinner, are abstract to a degree, and the more abstract are not necessarily the less intelligible... some very thick act descriptions are intelligible to very few - e.g. those of particular crafts. There are no general reasons for thinking that thick act descriptions are more comprehensible than thin ones... intelligibility and abstraction are in fact close and necessary allies rather than antagonists.' (O'Neill, 1996:68-9).

${ }^{21}$ I discuss communitarianism and relativism further in Gasper (1996).
} 
We do not lack recourse in ethical cases where we (whether within or across 
groups) cannot yet agree on classifications and descriptions, since we can also try to think in terms of principles. The principles used may need some basis of acceptability in the culture and indeed are likely to be there already; for our classification of cases into types invariably involves some use of principles, explicit (thus distanced from the case) or implicit (embodied in our choices). ${ }^{22}$ The principles may be in conflict with some other features in the culture. So insofar as our procedure involves thinning-down by reduction to the common denominators in disputants' moral languages, it is by appeal to those components with a claim to rank higher. Ethical particularists are so opposed to moral thinking in terms of abstract principles that they conclude too rapidly that moral disagreement (the presence of differing act descriptions from an normative point of view) equals value incommensurability and helplessness. But: 'It is only because so many practical principles are embedded in characters and institutions, so have become received views, that it can sometimes seem that fixing on a description is all that is required' (O’Neill, 1996:88). ${ }^{23}$

To sum up, while we saw the importance of reflection on examples concerning other people and/or imaginary situations, thick (sub-)culturally specific description is not always helpful there: both for discussion between cultures, as Walzer recognises, and even within a supposedly singular culture, since cultures are far more internally plural, underdefined, and internally contradictory and contested than suggested in communitarian discourse. Thickness is not necessarily more meaningful, even for insiders. In addition, much thinking and communication, including cross-culturally, proceeds with considerable effectiveness in terms of concrete, non-written examples. Their openness of texture and meaning, and ability thus to evolve in significance, further reduce the force of claims that 'here', 'in Rome', 'our' given and determinate moral language settles the ethical assessment of cases. Ironically, the 'thick' communitarian po

\footnotetext{
${ }^{22}$ We cannot apply ethical principles to cases until we have classified cases using some other principles, but those do not have to be ethical principles.

${ }^{23}$ In reality, in reaching judgements about what to do in a particular situation agents have to supplement and elaborate their more inclusive and abstract principles with more specific principles that are fashioned for more restricted domains... using their appropriate thick, or at least thicker, categories. However, the ethical weight and scope of these more specific principles... cannot be fixed without relying on a framework of more inclusive and determinate principles... (O’Neill, 1996:157).
} 
sition itself rests on what Sherry Ortner (1995) calls 'ethnographic thinness', a failure to closely observe.

The virtues of slimming - O'Neill on excluding irrelevant details when assessing justice

As in law so in (other) ethical argumentation, a great share of attention inevitably goes into deciding what type of case one is dealing with, and correspondingly which criteria should be adopted. Is ox-cultivation primarily a livestock use issue or a cropping issue? Does Toposa men's exclusive world end at the cattle camp or extend wherever cattle go? O'Neill argues that this case classification must be principled, by justifiable rules. Rather than rely on intuitions or traditions, the rule we advocate should be one that others could after thorough unforced consideration accept and adopt. This is a sterner requirement than that our rule for others be one we would accept for ourselves; for such a rule could be specially advantageous to us. Even this second possible requirement would often be demanding. In the Tanzania bilharzia case would Group B, who advocated not querying local practices, accept that say a Chinese doctor with superior knowledge who visited Europe during the centuries when bleeding the sick was common practice there should have stayed quiet to avoid disturbing the locals? Would they agree that they themselves should not be informed if, say, a Tanzanian doctor visiting the Netherlands observed that Dutch alternative pharmacists appear to have misclassified and misprescribed Tanzanian remedies? (Here we are using type 5 cases, imaginary but not impossible.)

Let us consider O'Neill's own principle further: a Kantian 'requirement of acting only on principles that can be acted on by all' (O'Neill, 1995:147). The proposal is that any rules of justice for a particular context have to be acceptable to all those involved, in conditions of no deceit, no fear of victimization, and ability by all to reject or renegotiate. Agreement given in conditions of unjust domination is not sufficient. O’Neill argues that building such agreements requires abstraction without idealization, and context-sensitivity without pure relativism (1991; 1996, Ch.2). We must not omit essential features from our analysis, nor must we include incidentals or biassing premises.

Since each situation has some unique features, abstraction is essential in any practical (i.e. choice oriented) reasoning which has to apply to more than a single 
situation - for example to a varied range of agents. The required components of abstraction will vary with the range of situations, range of agents, and the audience for the reasoning (O’Neill, 1996:61). For example: 'Justice will be blind to irrelevant differences: it should abstract from many features of particular cases. What is irrelevant depends on the case, but would nearly always include e.g. skin colour or race.... But justice should not be blind to relevant differences (which again depend on the case): it must avoid idealization of the actors concerned, implicit reference or bias towards certain types of individuals, e.g. men, the well-placed or the economically independent, the healthy, or the super-intelligent. Idealization means that certain individuals are implicitly privileged in the analysis; their position is taken as normal' (Gasper, 1996:651). Sometimes gender for example is a relevant distinguishing feature: we should know the gender of actors concerned if, say, we want to identify medical needs; in some other cases gender is not relevant and knowing genders might only bias choice.

We saw earlier how part of Rawls's theory of justice involves trying to abstract away from information that will allow selfish interests to bias social choices about rules applicable to all. Some feminist theorists have argued that the specific abstraction involved is biased to men, since the units whose interaction is to be governed appear to be households and intra-household division is not considered, yet household heads are predominantly male and do not almost invariably act equitably. Gender, they argue, is relevant information which should not be abstracted from.

So abstraction, thinning-out of case details, is required for understanding and judgement, but can go too far: exclusion of (morally) important differences is a danger. Conversely, context-sensitivity is required to include those relevant differences; but reference to the thick particularity of cases can degenerate into 'communitarian relativism, where too many particular local features, conventions and traditions, including prejudices and unjustified discriminations [e.g. that widows, or women in general, have no right to employment outside the home], are treated as defining relevant differences' (Gasper, 1996:652). In assessing whether women should be excluded from employment, or ox-ploughing or whatever, relativism merely asks -- in defining what sort of case this is and hence what type of information is relevant -- in which community/society are we arguing, and what are its criteria. It automatically eliminates the 
possibility of criticism of the criteria, even if those are defined mainly by the locally dominant powers. It endorses local powerholders and avoids questions of justice.

Both O'Neill and Rawls suggest the importance in ethical argumentation of enforcing ignorance about some matters. This thinness is to be attained not by always having starved, but by living fully, then reflecting and carefully excluding. Abstraction should be from rich materials; thin should follow thick, rather than be an undernourished forerunner. It can be more meaningful, not less.

Applying principles that have emerged from an abstracted analysis will often require complex judgement: a case may not clearly fit a principle and can be affected by multiple competing principles. The casuistic method of dealing with cases through comparison with sets of established exemplar cases is then sometimes relevant (Jonsen $\&$ Toulmin, 1988), provided use of its spaces for judgement is well motivated as well as shrewd.

The importance of being concrete and thick? - III: moral exemplars and moral motivation

The basis for morality is a willingness to consider other people's costs and benefits. Nagel warns that 'How would they feel?' arguments are not enough if some people lack that willingness to empathize. We saw that the 'How would I feel?' argument might sometimes still have effect: reasoning from and tidying up one's own feelings. It leads us to see a likely inconsistency (when I resent the theft of my umbrella as unfair, not only because it has been done to me, and yet want to do the same thing to someone else). However, by itself the question 'How would I feel?' does not tell us how such an inconsistency should be altered (whether by no longer feeling resentment at the theft, or by no longer wishing to take someone else's umbrella); nor does it ensure the motivational basis for doing anything about the inconsistency. We require attention both to feelings and to reasoning.

Feelings alone may be inconsistent and unreasonable; reasoning alone gives us insufficient direction or motivation. Possibly the feeling-reasoning dichotomy is overdrawn (Nussbaum, 1995). Could one ever think of aesthetic judgement as something divorced from feelings? So why should one for ethical judgement? We could think rather of training moral intelligence, in which cultured feelings are inherently a part; 
and we can link to virtue ethics, which focus on character. Given that--as parents know-'morality requires the development of the moral emotions' (Held, 1990:169), how does one foster them?

Benner describes, besides 'learning narratives', another type of story-telling by professionals. Constitutive or sustaining narratives 'exemplify positive notions about what is good' (1991:2), as the necessary partner to skills about how to promote what is good. They convey core values about why one is a professional (a nurse/ relief worker / policy adviser / teacher /...), including 'essential embodied human distinctions of worth, such as honor, courage and dignity' (Benner, p.4), and sustain one in difficult times. ${ }^{24}$

To promote fellow-feeling and motivation, there is then a role for, besides more general study and exposure and reflection on stressful choices, attention to inspiring cases and persons: moral exemplars. Tester (1997) and Singer (1993) discuss heroic individuals from the Holocaust, to show the reality of alternatives to participating in genocide. But these exemplars imply such demanding standards that, while they provide some inspiration, their impact might not be great. ${ }^{25}$ Slim cites therefore a variety of models in relief and development work: not only epic figures -- 19th century Europeans like Henri Dunant; 20th century Southern leaders like Chico Mendes and Steve Biko -- but especially, since those might be rather remote, from within the suffering groups themselves.

While the moral imagination of most international relief workers is still primarily conditioned by the traditional western humanitarian role model of the heroic intervenor, the great majority do also speak of encounters with impressive moral role models from inside the emergency... Many individual aid workers do carry with them the memory of the suffering and moral courage of a particular person or incident which sustains their own personal conviction as a relief worker. (Slim, 1997b: 256)

\footnotetext{
${ }^{24}$ From nursing, Benner cites narratives of 1 . the joy of healing and transcendence (especially if unexpected), 2. heroic rapid skilled intervention, 3. the growth of caring feelings, e.g. between patient and family, 4. endurance and communication in the face of extreme suffering.

${ }^{25}$ In a deep and now famous attack on the desirability of 'Moral Saints', Susan Wolf (1982) goes further; but rather than studying real exemplars she stays with hypothetical cases (both possible and impossible) of individuals who devote themselves overwhelmingly (and, she presumes, directly) either to the good of others (the less important variant she emphasises) or to the overall good of society (which also includes their own good). In contrast, Lawrence Blum (1988) studies a series of real figures to identify a variety of styles of morally exemplary figure, not a single 'saint' model. Onora O'Neill (1996, Ch.7) notes many relevant virtues to be exemplified, certainly not only the superogatory (beyond duty) virtues of moral heroism. See also the discussions of 'Degrees of Obligation' and 'Ethics and the Art of the Possible' in Gasper (1986).
} 
Away from the field, fiction and biography can give vicarious experience of others' joys and tragedies, and in addition of their responses, strength, skills and commitment. The literature of the struggle against apartheid is one rich school. At a lesser pitch, the sorts of biographies found in Johnson \& Bernstein (1983; on a range of Southern poor), Naipaul (1990; on varied Indian individuals and families) Leonard (1991; on notable Kenyan civil servants), and George (1997; on over a hundred Southern professionals) have something valuable to offer. The lives need not be dramatic nor the cases long. They do their 'thick' work by being holistic, contextualizing, giving personal flavour and extra perspectives.

Exemplars are those informative instances which convey patterns and associated affect to individuals, and assist them to more rapidly recall, interpret and respond. But most major decisions are made in and through organizations. How can organizations decide in complex and contested cases, under pressures of time and limits of information? Are there equivalent mechanisms, which could help them to be ready for rapid and reliable recall, interpretation and response? Here the notion of 'organizational conscience' enters (Slim, 1997b), an acquired and maintained capacity for better moral judgement by the organization. It is to be acquired and maintained through reflection and review of experience; recording, keeping and sharing of stories; and the facilitation and example given by organization leaders. But that is another story.

\section{VARIETIES OF TASK AND ARENA}

Cases have become central in recent ethics. Ethical theory does not give a master mechanism for making decisions; its role is more supplementary. Theories give categories and tests for examining cases, not laws for settling them. Nor is 'culture' the all-purpose problem solvent, as we saw. Existing moral languages within communities (a category equally imprecise) are not sufficiently comprehensive, clear or consistent to do more than provide resources for facing cases. Thus philosophers increasingly use the term 'practical ethics' not 'applied ethics'. This final section presents a tentative framework that indicates distinctive places in practical ethics for different styles of case-use and argumentation. 
The concepts we have used, such as thick and thin, are not sharp enough, and the variety of occasions, activities and sequences possible in practical discourse and ethical thought is too great to permit large generalizations. However it is worth outlining our findings about the presence of a range of types of case-example and of different moments in thought, marked by different purposes, in the form of an indicative table such as that below. One might distinguish more or fewer stages, depending on the context. They should not be seen as forming a fixed sequence. Many starting points, paths and feedbacks are possible. And sometimes the same case will be helpful at more than one, indeed several, stages.

Sensitization involves drawing and giving attention to situations, cases, issues, claimed ethical principles and formats. Its roles include to broaden the range of concerns, counter selfishness and myopia, mobilize emotions and motivation, raise doubts; to see, compare and feel. Its case examples should be vivid and involving, and preferably concern real people. They can be simple or rich, but not too rich for absorption. As suggested earlier, simple cases with little information sometimes have a useful role too, of drawing out commentators' presumptions. Anecdotal practice stories can fit well, as can more extended cases. Providing vicarious experience is vital. This stage matches the role Goulet $(1971,1995)$ emphasizes for development ethics: to offer grounded existential witness. Goulet stresses phenomenological study to reveal and clarify the values and value-choices encountered in situations. As this becomes more refined and analytical it merges into later stages.

Problem analysis seeks to build on prior awareness and concerns, to discipline emotions and argumentation. It may lead into theorization, to clarify and also add and revise concepts and frameworks, strengthen and extend logic and consistency, compare systems of values. Cases there must be clear and purposeful, in the senses suggested earlier: giving sustained focus; identifying relevant differences and ignoring irrelevant ones; and so on. They should probably not concern real people, for that can bring distraction by extraneous (and also opportunistic) considerations. Constructs from theorization will no doubt affect the direction of vision and forms of perception in other stages of work; but those stages retain their independent basis and thus in turn can enrich and discipline theorization. 


\begin{tabular}{|l|l|l|}
\hline \multicolumn{1}{|c|}{$\begin{array}{c}\text { Stage/focus of ethical/ } \\
\text { practical discourse }\end{array}$} & \multicolumn{1}{|c|}{ Roles of cases/examples } & \multicolumn{1}{c|}{ Typical cases/examples } \\
\hline Exposure & $\begin{array}{l}\text { Cases can sensitize and motivate: } \\
\text { Sensitize to situations, issues, ethi- } \\
\text { cal claims; } \\
\text { Build fellow-feeling; } \\
\text { Convey notions about what is good. }\end{array}$ & $\begin{array}{l}\text { Vivid, engrossing. } \\
\text { About real people. } \\
\text { Some thin, some thick, but espe- } \\
\text { cially intermediate. } \\
\text { Including anecdotes, choice } \\
\text { situations, 'constitutive narra- } \\
\text { tives', moral exemplars. }\end{array}$ \\
\hline $\begin{array}{l}\text { Everyday analysis of a } \\
\text { real problem case }\end{array}$ & $\begin{array}{l}\text { Other cases/examples exemplify } \\
\text { patterns and possibilities } \\
\text { (as in other stages too); and thus } \\
\text { aid analysis of real cases faced }\end{array}$ & $\begin{array}{l}\text { Striking paradigm cases. } \\
\text { Anecdotes and 'learning narra- } \\
\text { tives', including about stances, } \\
\text { options, limits. }\end{array}$ \\
\hline $\begin{array}{l}\text { More formal theorization } \\
\text { (when required) }\end{array}$ & $\begin{array}{l}\text { Cases here should deepen and sys- } \\
\text { tematize analysis: } \\
\text { help to clarify and discipline ideas; } \\
\text { test coherence of candidate theories. }\end{array}$ & $\begin{array}{l}\text { Clear, sharply focused. } \\
\text { Not about real people. } \\
\text { Thin. } \\
\text { Including choice situations and } \\
\text { impossible scenarios. }\end{array}$ \\
\hline $\begin{array}{l}\text { More theorized analysis of } \\
\text { a real problem case } \\
\text { (when required) }\end{array}$ & $\begin{array}{l}\text { Reference to other cases is to sup- } \\
\text { port choice-making (and future ob- } \\
\text { servation and theorizing). } \\
\text { To help show which theories are } \\
\text { relevant to a problem context. } \\
\text { To test relevance and realism of } \\
\text { candidate theories. }\end{array}$ & $\begin{array}{l}\text { 1) In training: rich real practice } \\
\text { cases; and well-theorized (often } \\
\text { thinned) cases } \\
\text { 2) In practice: comparison with } \\
\text { well-theorized (often thinned) real } \\
\text { cases. }\end{array}$ \\
\hline $\begin{array}{l}\text { No support practice } \\
\text { compromise }\end{array}$ & $\begin{array}{l}\text { Including: to help to build and } \\
\text { maintain attitudes, character. }\end{array}$ & $\begin{array}{l}\text { 'Learning narratives', including } \\
\text { about relationships, stresses, tac- } \\
\text { tics. } \\
\text { Thick or intermediate. } \\
\text { Moral exemplars. }\end{array}$ \\
\hline
\end{tabular}

Practice too must draw on other stages of work as required, while recognizing the inevitable limits and simplifications of one's claimed experiential base and theoretical equipment. One is particularly interested in practice to see where different metaphysical starting points and theoretical routes lead to the same recommendations. Casethinking helps to inform and complement proposed policies, principles, ethics guidelines and codes. The cases referred to must (again) be rich and real. They can help give a feel for context and thus some ability to judge when particular conceptualizations and models fit. The cases should include 'practice stories', and convey something about the attitudes, character(s) and skills helpful in dealing with complexity, uncertainty, limits of theory and plurality of viewpoints, stress, and the need for choices, negotiation, compromises and creativity. The experience and learning from practice-related ethics 
must also feed back into the scanning for and reaction to evidence, and into (re-) conceptualization and theorizing.

As an example across these stages, consider the ethics-related work of Amartya Sen. Sen is primarily a theorist. But his theorizing has maintained respectable and fruitful balances in relation to experiential basis and practical role. Unlike some economists and philosophers, his choice of examples does not reflect a narrow life nor mainly a priority to convenience in a preset style of theorizing. His motivating cases are wide-ranging, sometimes intense, and not concealed: including the Great Bengal famine of 1943-5 in which millions died while food was available, which he lived through as a child. These cases mobilize audience sympathies and ready them for the disciplined conceptualization, model-building and -testing that will follow. His theorizing has then analysed, for greater clarity and tractability, abstracted formulations such as for the displaced wage-labourer or artisan who can lack effective entitlement and starve in the face of food. Sen typically finds or already has empirical counterparts for his abstracted cases: he moves to 'thin' theorizing after thinking on real cases, or begins thin, with a hypothetical case, but then seeks to confirm its relevance through examining real counterparts and checking that he has not left out key features. His style of theorizing generally leads to procedural advice not to policy edicts -- 'pay attention also to factors A and B', not 'conclude and do as follows' -- and is thus conducted without forgetting the corrigibility and incompleteness of abstracted theorization. And characteristically it is embellished or, rather, reconnected to richer, real life, by anecdote and quotation.

In sum, I have suggested that we become more aware of a variety of modes of recourse to cases and illustrations in practical ethics and development practice, each with its own pros and cons; that some distinctive considerations arise in normative argumentation, justifying this type of separate discussion; and that to some extent different types of argumentation and of use of cases figure in different stages of work. My pictures of the range of types of case, of stages, and of the issues and tendencies arising can each be improved. I hope though to have given a usable introduction. 


\section{REFERENCES}

Apffel Marglin, F., 1990. Smallpox in Two Systems of Knowledge. Pp.102-44 in F. Apffel Marglin \& S. Marglin (eds.), Dominating Knowledge: Development, Culture and Resistance. Oxford: Clarendon.

Arendt, H., 1982. Lectures on Kant's Political Philosophy. Chicago: Univ. of Chicago Press

Baker, R., 1994, Summer in the Balkans: Laughter and Tears after Communism, West Hartford: Kumarian Press.

Benner, P., 1991 'The role of experience, narrative and community in skilled ethical comportment', Advances in Nursing Science, 14(2), 1-21.

Blanchard, W., 1986. What Does Fairness Mean and Can We Measure It? Policy Studies Journal, 15(1), 29-54.

Blum, L., 1988, Moral Exemplars, Midwest Studies in Philosophy, XIII, 196-221.

Bulmer, M., \& Warwick, D., eds., 1983. Social Research in Developing Countries. Chichester: John Wiley

Carr, E.H., 1961. What is History? Penguin.

Caufield, C., 1998, Masters of Illusion - the World Bank and the Poverty of Nations. London: Pan.

Cooper, R., \& Packard, R., 1997. Introduction. Pp.1-41 in Cooper \& Packard (eds.), International Development and the Social Sciences, Berkeley: University of California Press.

Creswell, J., 1998. Qualitative Inquiry and Research Design - Choosing Among Five Traditions. Thousand Oaks, CA: Sage.

Crocker, D., 1991. Toward Development Ethics. World Development, 19(5), 457-83.

Deming, W.E., 1975. The Logic of Evaluation. In M. Guttentag \& E. Struening (eds.), Handbook of Evaluation Research, Sage.

de Waal, A., 1997. Famine Crimes - Politics and the Disaster Relief Industry in Africa. London: James Currey.

Fairhead, J., \& Leach, M., 1997. Webs of Power and the Construction of Environmental Policy Problems: Forest Loss in Guinea. Pp.35-57 in Grillo \& Stirrat (eds.). 
Forester, J., 1993. Learning from Practice Stories - the Priority of Practical Judgement. Pp.186-209 in F. Fischer \& J. Forester (eds.), The Argumentative Turn in Policy Analysis and Planning, Duke Univ. Press.

Frank, L., 1986. The Development Game. Granta, 20, 229-43. Also in M. Rahnema (ed.), The Post-Development Reader, 1997, London: Zed.

Gardner, K., 1997. Mixed Messages: Contested 'Development' and the 'Plantation Rehabilitation Project'. In Grillo \& Stirrat eds., pp.133-56.

Gasper, D., 1986 'Distribution and Development Ethics' i Development Studies - Critique and Renewal, edited by R. Apthorpe \& A. Krahl, Leiden: Brill, pp.136-203.

Gasper, D., 1993: Equity, equality and appropriate distribution - multiple interpretations and Zimbabwean usages. Pp.35-62 in Conflict and Change in the 1990s, eds. A. Carty \& H. Singer, London: Macmillan.

Gasper, D., 1994. Development Ethics - an emergent field? Pp.160-185 In Market Forces and World Development, eds. R. Prendergast \& F. Stewart, London: Macmillan. Revised version as Gasper, 1997.

Gasper, D., 1994b: Review of D. Porter et al. (1991), Development and Change, 25( )

Gasper, D., 1996: Culture and Development Ethics - needs, women's rights, and Western theories. Development and Change, 27(4), 627-61.

Gasper, D., 1997. Development Ethics - An Emergent Field? Pp.25-43 \& 182-5 in C. Hamelink (ed.), Ethics and Development - On Making Moral Choices in Development Cooperation, 1997, Kampen: Uitgeverij Kok.

Gasper, D., 1999a, “Drawing a Line” - ethical and political strategies in complex emergency assistance', European J. of Development Research, 11(2).

Gasper, D., 1999b, 'Evaluating the "logical framework approach" - towards learningoriented development evaluation', Public Administration and Development.

Gasper, D., 1999c, 'Ethics and the conduct of international development aid - charity and obligation', Forum for Development Studies (Oslo).

George, S., 1997. Third World Professionals and Development Education in Europe Personal Narratives and Global Conversations. Delhi: Sage.

Goulet, D., 1971, The Cruel Choice, New York: Athenaeum.

Goulet, D., 1995. Development Ethics. London: Zed. 
Grillo, R., \& Stirrat, R., eds., 1997. Discourses of Development - Anthropological Perspectives, Oxford: Berg.

Harrell-Bond, B., 1986. Imposing Aid: Emergency Assistance to Refugees. Oxford: OUP Held, V., 1990. Reason, Gender and Moral Theory. Pp.166-9 in P. Singer (ed.), 1994.

Hirschman, A., 1967, Development Projects Observed. Brookings.

Jamieson, D., 1991, 'Method and Moral Theory', pp.476-87 in P. Singer (ed.), $A$ Companion to Ethics, Oxford: Blackwell.

Johnson, H., \& Bernstein, H. (eds.), 1983. Third World Lives of Struggle. London: Heinemann.

Jonsen, A., \& Toulmin, S., 1988, The Abuse of Casuistry, Berkeley: U. of California Press. Kuhn, T., 1977. The Essential Tension. Chicago: Univ. of Chicago Press.

Leonard, D., 1992. African Successes: four public managers of Kenyan rural development. Berkeley: Univ. of California Press.

Li, Xiarong, 1995. Gender Inequality in China and Cultural Relativism. Pp.407-25 in Nussbaum \& Glover eds.

Nagel, T., 1987. The Objective Basis of Morality, pp.155-8 in Singer, P. (ed.), 1994

Naipaul, V.S., 1990. India: A Million Mutinies Now. London: Heinemann / Minerva.

Nozick, R., 1974, Anarchy, State and Utopia, New York: Basic Books.

Nussbaum, M., 1995. Emotions and Women's Capabilities. Pp.360-95 in Nussbaum \& Glover (eds.).

Nussbaum, M., 1997 Poetic Justice - Literary Imagination and Public Life.

Nussbaum, M. \& Glover, J. (eds.), 1995. Women, Culture, and Development. Oxford: Clarendon.

Nyamwaya, D., 1997. Three Critical Issues in Community Health Development Projects in Kenya. Pp.183-201 in Grillo \& Stirrat (eds.).

O’Neill, O., 1986, 'The power of example', Philosophy, 61, 5-29.

O’Neill, O., 1991. Justice, Gender and International Boundaries. British J. of Political Sci., 20, 439-59.

O’Neill, O., 1995. Justice, Capabilities and Vulnerabilities. Pp.140-52 in Nussbaum \& Glover (eds.)

O’Neill, O., 1996. Towards Justice and Virtue - a constructive account of practical reasoning. Cambridge: Cambridge Univ. Press. 
Ortner, S., 1995, 'Resistance and the Problem of Ethnographic Refusal', Comparative Studies in Society and History, 37(1), 173-93.

Øyhus, A.O., 1998. Universal Soldiers: The Developers - Their Technology and Ethics. Paper to conference on Ethics and Development, Norwegian Association for Development Research, Skjetten, June 5-6.

Padaki, V. (ed.), 1995. Development Intervention and Programme Evaluation. Delhi: Sage.

Patton, M.Q., 1997. Utilization-Focused Evaluation, 3rd edition. Thousand Oaks, CA: Sage.

Peattie, L., 1987. Planning -- Rethinking Ciudad Guyana. Ann Arbor: Univ. of Michigan Press.

Pfund, A., \& Dietz, T., 1988. An Impact Identification Method for Development Project Evaluation. Policy Studies Journal, 8(1), 137-45.

Porter, D., et al., 1991. Development in Practice. London: Routledge.

Posthumus, B., 1997. Making Moral Choices in Development Cooperation - The Necessity of Diversity. Report on conference on ethics and development, March 20-22, 1997, Soesterberg, The Netherlands. NVCO: Soesterberg.

Pottier, J., 1997. Towards an Ethnography of Participatory Appraisal and Research. Pp.203-227 in Grillo \& Stirrat (eds.).

Richards, H., 1985. The Evaluation of Cultural Action: an evaluative study of the Parents and Children Program (PPH). London \& Basingstoke: Macmillan.

Roe, E., 1989, 'Folktale Development', The American J. of Semiotics, 6(2/3), 277-89.

Sen, A., 1981, Poverty and Famines, Oxford: Oxford Univ. Press.

Sen, A., 1984, Resources, Values, and Development, Oxford: Blackwell.

Shadish, W., et al., 1991. Foundations of Program Evaluation - Theories of Practice. Newbury Park, CA: Sage.

Shawcross, W., 1984. The Quality of Mercy - Cambodia, Holocaust and Modern Conscience. London: Andre Deutsch.

Singer, P., (ed.), 1994. Ethics. Oxford: Oxford Univ. Press.

Sivaramakrishnan, K., \& Agrawal, A. (1998), 'Regional Modernities in Stories and Practices of Development', mimeo. 
Slim, H., 1997a, 'Doing the Right Thing - Relief Agencies, Moral Dilemmas and Moral Responsibility in Political Emergencies and War', Studies on Emergencies and Disaster Relief, no.6, Uppsala: Nordiska Afrikainstitutet.

Slim, H., 1997b, 'Doing the Right Thing - ...', Disasters, 21(3), 244-57. (Version without cases)

Stake, R., 1967. The countenance of educational evaluation. Reprinted in D. Hamilton et al. (eds., 1977), Beyond the Numbers Game, Basingstoke \& London: Macmillan.

Stake, R., 1978. The case study method in social inquiry. Educational Researcher, 7, 5-8.

Stake, R., 1980. Program evaluation, particularly responsive evaluation. In W.B. Dockrell \& D. Hamilton (eds.), Rethinking Educational Research, pp.72-87. London: Hodder \& Stoughton.

Stake, R., 1995. The Art of Case Study Research. Thousand Oaks, CA: Sage.

Stake, R., \& Trumbull, D., 1982. Naturalistic generalizations. Review Journal of Philosophy and Social Science, 7, 1-12.

Tester, K., 1997. Moral Culture. London: Sage.

Uphoff, N., 1996. Learning from Gal Oya. London: Intermediate Technology Publications.

Walzer, M., 1994. Thick and Thin - Moral Argument at Home and Abroad. Notre Dame, Indiana: Univ. of Notre Dame Press.

Wolf, S., 1982 'Moral Saints’, Journal of Philosophy, 79, 419-39. 


\section{ISS WORKING PAPERS}

\section{Papers can be purchased or ordered from:}

The Bookshop

P.O. Box 29776

2502 LT The Hague

The Netherlands

Telefax: 31704260799

A complete list of Working Papers is available from the Bookshop.

\section{GENERAL SERIES \\ ISSN 0921-0210}

273 Batbayar Badamdorj: Problems and Perspectives of Public Administration Reform: the Case of the Executive Branch of the Government of Mongolia (April 1998).

274 Saturnino M. Borras Jr.: The Bibingka Strategy to Land Reform and Implementation: Autonomous Peasant Mobilisations and State Reformists in the Philippines (April 1998).

275 Jan Nederveen Pieterse: Critical Holism and the Tao of Development (April 1998).

276 Jos Mooij: Real Targeting. The Case of Food Distribution in India (July 1998).

277 A. Geske Dijkstra: Crisis, Adjustment and the Dynamics of Gender Relations in Central America and the Caribbean (August 1998).

278 Nussara Sawatsawang: Thailand's Financila Crisis of 1997: A Survey and Critique of Dominant Explanations (August 1997).

279 Saskia Wieringa: Rethinking Gender Planning: A Critical Discussion of the use of the Concept of Gender (September 1998).

280 Algis Prazauskas: Ethnicity, Nationalism and Politics (September 1998).

281 Cristóbal Kay: Relevance of Structuralist and Dependency Theories in the Neoliberal Period: A Latin American Perspective (October 1998).

282 Erhard Berner: Poverty Alleviation and the Eviction of the Poorest: Urban Land Transfer Programs in the Philippines (October 1998).

283 Sandro Sideri: The World Economy: The Crisis in Financial Markets and the Risk of a Global Depression (December 1998).

284 Xu Li: Gender Relations and Reproductive Decision-Making in the context of Rural China of the PostReform Period (January 1999).

285 Marco V. Sánchez Cantillo: Implications of the Opening of Trade on Production, Income Distributionand the Balance of Trade: A Computable General Equilibrium Model for Costa Rica with Counterfactual Simulations (January 1999).

286 Peter Waterman: Of Saints, Sinners and Compañeras: Internationalist Lives in the Americas Today (February 1999).

287 Nicholas Awortwi: The Riddle of Community Development: Factors Influencing Organisation, Participation and Self-Management in 29 African and Latin American Communities (February 1999).

288 George Kurian: Empowering Conditions in the Decentralisation Process: An Analysis of Dynamics, Factors and Actors in Panchayati Raj Institutions from West Bengal and Karnataka, India (March 1999).

289 Bridget O'Laughlin In defence of the household: Marx, gender and the utilitarian impasse (May 1999)

290 Claudius Preville How will free trade impact on net global economic welfare?: an analysis of the EU'sbanana market structure (June 1999)

291 A.H.J. (Bert) Helmsing Competitive response, innovation and creating an innovative milieu: The case of manufacturing industry in Bulawayo, Zimbabwe (June 1999) 
292 Rob Vos, Margarita Velasco and Edgar Labiastida Economic and social effects of "el Niño" in Ecuador, 1997-8 (July 1999)

293 Andrea Manuelli Direct investment and export from Italian industry: divergences and convergences of a small enterprise economy. (July 1999)

294 Edsel Sajor Cutting trees and the dynamics of social change: The case of the Ifugao Muyong in the Philippine uplands (August 1999)

295 Aaron Pollack Epistemological Struggle and International Organizing: applying the experience of the Zapatista Army of National Liberation (August 1999)

296 Amrita Chhachhi "Gender, Flexibility, Skill and Industrial Restructuring: The ElectronicsIndustry in India

297 Des Gasper Ethics and the conduct of International development Aid: Charity and Obligation(September 1999)

298 Max Spoor Agrarian Transition in Former Soviet Central Asia: A Comparative study of Kazakhstan, Kyrgyzystan and Uzbekistan (September 1999)

299 Erwin Alampay Organizations in development: The changing nature of service provision in the Philippines (October 1999)

Working papers series/ISS. Sub-series on

MONEY, FINANCE AND DEVELOPMENT

ISSN: 0921-0202

62. Alemayehu-Geda, The Historical Origin of African Debt and External Finance Problems (May 1997).

WOMEN, HISTORY AND DEVELOPMENT: themes and issues

ISSN: 0921-0199

19 Shiney Varghese: Women and Agrarian Change: A Historical Analysis of Dangs: 1870s - 1990s (February 1999). 